\title{
TRATAMENTO LAPAROSCÓPICO DE PERIAPENDICITE CAUSADA POR DISPOSITIVO INTRA-UTERINO
}

\author{
Júlio Cezar Uili COELHO, Carolina Gomes GONÇALVES e \\ Christie Michelle GRAF
}

\begin{abstract}
RESUMO - Racional - Dispositivo intra-uterino pode perfurar o útero e causar várias complicações. Objetivo - Descrever um caso de tratamento laparoscópico de periapendicite causada por dispositivo intra-uterino. Material e Métodos - Jovem do sexo feminino apresentou dor em fossa ilíaca direita de 4 dias de duração. No exame físico, apresentava dor abdominal localizada em fossa ilíaca direita, com discreta renitência de parede e dor à percussão e descompressão brusca na região. A ultra-sonografia evidenciou dispositivo intra-uterino fora do útero, na fossa ilíaca direita. Resultados - À laparoscopia, observou-se massa inflamatória que consistia do dispositivo intra-uterino totalmente bloqueado pelo mesoapêndice e apêndice. Apendicectomia e retirada do dispositivo foram realizadas. Conclusão - A laparoscopia permite o tratamento adequado da periapendicite causada por dispositivo intra-uterino, inclusive com avaliação adequada de toda a região pélvica para excluir lesões associadas.
\end{abstract}

DESCRITORES - Apendicite. Abdome agudo. Dispositivos intra-uterinos, efeitos adversos. Apendicectomia. Laparoscopia.

\section{INTRODUÇÃO}

Perfuração do útero por dispositivo intra-uterino (DIU) é complicação rara e grave, ocorrendo a cada 350 a 2.500 inserções ${ }^{(5)}$. Uma vez na cavidade abdominal, o DIU pode comprometer vários órgãos vizinhos, como a bexiga, o intestino delgado, o retossigmóide e o apêndice vermiforme $e^{(1,2,3,4,5,6)}$. Raros casos de apendicite ou periapendicite causados por DIU têm sido descritos na literatura ${ }^{(2,4)}$. No Brasil, esta complicação ainda não foi relatada.

O objetivo do presente relato foi descrever um caso de periapendicite causada por DIU.

\section{RELATO DO CASO}

Paciente de 23 anos, do sexo feminino, apresentou história de dor em fossa ilíaca direita, com 4 dias de evolução, sem fator desencadeante. Não apresentava náuseas, vômito ou febre. Ao exame físico, apresentava dor abdominal localizada em fossa ilíaca direita, com discreta renitência de parede e dor à percussão e descompressão brusca na região. Relatou história de implantação uterina de DIU 40 dias antes do início da dor. Foi realizada ultra-sonografia abdominal, que evidenciou presença de DIU na fossa ilíaca direita, próximo ao ovário direito, mas fora do útero.

A paciente foi, então, encaminhada para o centro cirúrgico para laparoscopia. Na inspeção da cavidade, foi visualizado líquido livre na fossa ilíaca direita, em pequena quantidade e de aspecto seroso. O útero se apresentava hiperemiado, principalmente em fundo uterino, com mínimas aderências em porção posterior, porém não havia sinal de perfuração evidente. Observou-se massa inflamatória em fossa ilíaca direita. Na abordagem desta, constatou-se a presença do DIU, que se encontrava totalmente envolvido pelo mesoapêndice e apêndice. A apendicectomia foi realizada sem dificuldades. $\mathrm{O}$ apêndice com todo o DIU foi retirado. Não foi realizada drenagem.

A paciente apresentou boa recuperação pós-operatória, sem complicações. Obteve alta 12 horas após a operação. O exame anatomopatológico evidenciou periapendicite aguda e crônica.

Trabalho realizado no Serviço de Cirurgia Geral do Hospital Nossa Senhora das Graças, Curitiba, Paraná.

Endereço para correspondência: Dr. Júlio Coelho - Rua Bento Viana, 1140 - ap. 2202 - 80240-110 - Curitiba, PR. 


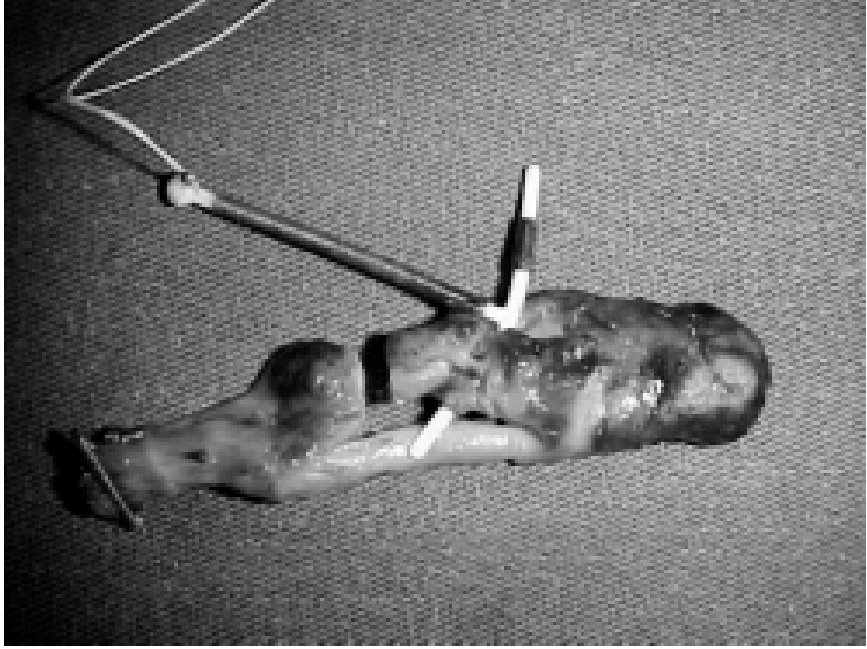

FIGURA 1 - Dispositivo intra-uterino bloqueado pelo mesoapêndice e apêndice

\section{DISCUSSÃO}

Perfuração uterina pode ocorrer durante a inserção de DIU ou posteriormente ${ }^{(5)}$. Dentro da cavidade peritonial, o DIU pode causar formação de fibrose, dor abdominal, infertilidade, obstrução intestinal e perfuração para órgãos vizinhos, como bexiga e o retossigmóide ${ }^{(1,2,3,4,5,6)}$. Raros casos de apendicite ou periapendicite também têm sido descritos ${ }^{(2,4)}$.

A apresentação clínica de apendicite aguda causada por DIU é similar à da apendicite por outras causas. Os sintomas podem iniciar logo após a inserção do dispositivo ou até meses depois ${ }^{(2,4)}$. A etiologia da apendicite pode ser estabelecida no pré-operatório tanto pela radiografia simples, como pela ultra-sonografia do abdome, que evidenciam o DIU na fossa ilíaca direita ou junto ao apêndice ${ }^{(4)}$. Na paciente, objeto deste relato, a ultra-sonografia evidenciou implantação de DIU na cavidade abdominal, em fossa ilíaca direita, próxima ao ovário.

O tratamento consiste na realização da apendicectomia. A via laparoscópica permite realizar a liberação de bridas e a remoção do apêndice com segurança ${ }^{(2)}$. Além do mais, a laparoscopia tem a vantagem de permitir avaliação adequada de toda a região pélvica para excluir lesões associadas, inclusive o local de perfuração do útero. Outras complicações associadas, como perfuração de intestino delgado e grosso ou da bexiga, podem também ser eficazmente corrigidas por esta via. Entretanto, a presença de aderências firmes e intensas, principalmente se próximas a alças intestinais, pode dificultar a dissecção do DIU e aumentar a possibilidade de perfuração intestinal. Nestas condições, o cirurgião deve considerar a possibilidade de conversão para laparotomia, na dependência da sua experiência ${ }^{(2)}$.

Coelho JCU, Gonçalves CG, Graf CM. Laparoscopic treatment of peri-appendicitis caused by intrauterine contraceptive device. Arq Gastroenterol $2003 ; 40(1): 45-46$

ABSTRACT - Background - Intrauterine device may perforate the uterus and cause several complications. Aim - To report a case of laparoscopic treatment of peri-appendicitis caused by intrauterine device. Patient and Method - A young female presented with pain in the right lower abdomen of 4 days of duration. On the physical examination, she had localized abdominal pain in the right lower abdomen with discrete guarding and pain on percussion and rebound tenderness. Ultrasonography showed an intrauterine device outside of the uterus, in the right lower of the abdomen. Result - At laparoscopy, an inflammatory mass that consisted of the intrauterine device blocked by the mesoappendix and the appendix was observed. Appendectomy and removal of the intrauterine device were performed. Conclusion - Laparoscopy allows adequate treatment of peri-appendicitis caused by intrauterine device, inclusive with complete evaluation of the entire pelvic region to rule out associated complications

HEADINGS - Appendicitis. Abdomen, acute. Intrauterine devices, adverse effects. Appendectomy. Laparoscopy.

\section{REFERÊNCIAS BIBLIOGRÁFICAS}

1. Gorsline JC, Osborne NG. Management of the missing intrauterine contraceptive device: report of a case. Am J Obstet Gynecol 1985;153:228-9.

2. Ohana E, Sheiner E, Leron E, Mazor M. Appendix perforation by an intrauterine device. Eur J Obstet Gynecol Reprod Biol 2000;88:129-31.

3. Sepúlveda WH, Ciuffardi I, Olivari A, Gallegos O. Sonographic diagnosis of bladder perforation by an intrauterine device. A case report. J Reprod Med 1993;38:911-3.
4. Serra I. Appendicitis caused by an intrauterine contraceptive device. Br J Surg 1986;73:927-8

5. Sogaard K. Unrecognized perforation of the uterine and rectal wall by an intrauterine contraceptive device. Acta Obstet Gynecol Scand 1993;72:55-6.

6. Zakin D, Stern WZ, Rosenblatt R. Complete and partial uterine perforation and embedding following insertion of intrauterine devices. I. Classification, complications, mechanism, incidence, and missing string. Obstet Gynecol Surv 1981;36:335-53.
Recebido em 26/11/2001. Aprovado em 22/10/2002. 